\title{
Synthesis and ESR Spectroscopy Complexes of Copper(II) with Acyl- and Aroylhydrazones of Methyl Ester of 5,5-Dimethyl-2,4-Dioxohexanoic Acid
}

\author{
Tursunov Murod Amonovich ${ }^{1,}$, , Sevinchova Dilobar Nematovna ${ }^{2}$, Avezov Kuvondik Giyasovich ${ }^{1}$, \\ Umarov Bako Bafayevich ${ }^{1}$, Ganiyev Bakhtiyor Shukurullayevich ${ }^{1}$, \\ Savriyeva Nigina Qahramon Qizi ${ }^{1}$ \\ ${ }^{1}$ Department of Chemistry, Bukhara State University, Bukhara City, Uzbekistan \\ ${ }^{2}$ Department of Medical Chemistry, Bukhara State Medical Institute, Bukhara City, Uzbekistan
}

Email address:

tursunovma@mail.ru (T. M. Amonovich), b.ganiyev1990@gmail.com (G. B. Shukurullayevich)

*Corresponding author

\section{To cite this article:}

Tursunov Murod Amonovich, Sevinchova Dilobar Nematovna, Avezov Kuvondik Giyasovich, Umarov Bako Bafayevich, Ganiyev Bakhtiyor Shukurullayevich, Savriyeva Nigina Qahramon Qizi. Synthesis and ESR Spectroscopy Complexes of Copper(II) with Acyl- and Aroylhydrazones of Methyl Ester of 5,5-Dimethyl-2,4-Dioxohexanoic Acid. American Journal of Heterocyclic Chemistry.

Vol. 6, No. 2, 2020, pp. 24-29. doi: 10.11648/j.ajhc.20200602.12

Received: July 24, 2020; Accepted: August 19, 2020; Published: September 3, 2020

\begin{abstract}
The method of ESR is widely used for the investigation of electronic construction and the geometrical structure of the polynuclear complexes of the transition metals. The majority of the well-known experimental works had been done using monocrystals and polycrystalline examples. Construction of mononuclear complexes of the copper(II), the nature of antiferromagnetic exchange interaction, and its value was the object of the discussion by the scientists and that issue is being checked in the article. Complex compounds of copper(II) with 5,5-dimethyl-2,4-dioxohexane acid $\left(\left(\mathrm{H}_{2} \mathrm{~L}^{1}-\mathrm{H}_{2} \mathrm{~L}^{11}\right)\right.$ methyl ether aroylhydrazones were synthesized and studied. The interaction of alcohol solutions of the $\mathrm{H}_{2} \mathrm{~L}^{1}-\mathrm{H}_{2} \mathrm{~L}^{11}$ ligands with an aqueous ammonia solution of copper(II) acetate synthesized green fine-crystalline copper(II) complexes. Complexes investigation by the method of ESR spectroscopy, of the studying the magneto chemical properties of copper(II) complexes. If for the complex compound $\mathrm{CuL}^{1} \cdot \mathrm{NH}_{3}$, which has a cyclopentanone ring $\beta$-diketone fragment, the EPR parameters have the $\beta$ a substituent for the $\alpha^{2}=0.82$; value: $\mathrm{g}=2.099, \mathrm{a}_{\mathrm{Cu}}=89.53 \mathrm{e}, \mathrm{a}_{\mathrm{N}}=12.81 \mathrm{e}$, then for $\mathrm{CuL}^{4} \cdot \mathrm{NH}_{3}$ with a cyclohexane ring substituent these values are in the range: $\mathrm{g}=2,101, \mathrm{a}_{\mathrm{Cu}}=87,48 \mathrm{e}, \mathrm{a}_{\mathrm{N}}=13,02 \mathrm{e}, \alpha^{2}=0,82$.
\end{abstract}

Keywords: Aroylhydrazone, Ethyl Ether of 5,5-dimethyl-2,4-dioxohexane Acid, Antiferromagnitic, Flat Square, Superposition

\section{Introduction}

In recent years, research in the field of coordination chemistry has been characterized by a stable tendency to shift the center of gravity from simple mononuclear compounds to more complex systems, which is primarily due to the search for new molecular materials and catalytic systems. These works, along with the consideration of their geometric and electronic structure, allow us to draw reasonable conclusions and predict the ways of directed synthesis of complex compounds with specified properties [1-3].

In contrast to $\mathrm{Ni}(\mathrm{II})$, the IR spectra of $\mathrm{Cu}$ (II) complexes similar in composition do not change noticeably when the complexes are dissolved in $\mathrm{CCl}_{4}$. They can be obtained by reacting an aqueous solution of copper(II) chloride$\mathrm{CuCl}_{2} \cdot 2 \mathrm{H}_{2} \mathrm{O}$ with an alcohol solution of the ligand with the subsequent addition of a dilute aqueous solution of ammonia or by mixing alcohol solutions of copper(II) acetate and the ligand. In the IR spectra of the obtained $\mathrm{m}(\mathrm{HL})_{2}$ complexes, an intense band is observed in the region of $1735-1750 \mathrm{~cm}^{-1}$, which should be attributed to the valence vibrations of the $\mathrm{C}=\mathrm{O}$-bond of the uncoupled $\mathrm{COOC}_{2} \mathrm{H}_{5}$ ester group. When the complex is formed due to nitrogen of the enhydrazine form, the bands of valence vibrations of this bond must show 
a significant long-wave shift due to the inclusion of the $\mathrm{C}=\mathrm{O}$ bond in the composition of the conjugated six-membered chelated metal cycle.

According to the authors, as in the case of Nickel complexes, copper(II) complexes arise by coordinating the metal at the oxygen atom of the anion that corresponds to the $\alpha$-oxyazine tautomer form. The appearance of two intense absorption bands at 1380 and $1550 \mathrm{~cm}^{-1}$ due to fluctuations in the $\mathrm{NCO}^{-}$group is consistent with this structure of the complexes [4].

Thus, the formation of a five-membered chelate cycle is energetically more profitable than the formation of a sixmembered chelate cycle corresponding to the enhydrazine form. Consequently, there is no coordination of the $\mathrm{C}=\mathrm{O}$ bond to the $\mathrm{Cu}(\mathrm{II})$ ion in this solvent, and the complexes probably have a flat-square structure, similar to the complexes with para-substituted aroylhydrazones of aldehydes, ketones, $\beta$ - ketoaldehides and $\beta$-ketoesters, as well as various other derivatives with hydrazides [5, 6]. This conclusion is fully confirmed by the data from the ESR spectra of the complexes. The values of the ESR parameters are close to the parameters of $\mathrm{Cu}$ (II) complexes with a flatsquare structure consisting of two five-membered metal cycles located in a TRANS-position relative to each other. Like copper(II) VCS with ketone aroylhydrazones [7, 8] and thiobenzoylhydrazones of aldehydes, copper(II) VCS with AUE aroylhydrazones, according to ESR spectra $[6,9,10]$, when dissolved in donor solvents, form adducts.

\section{Experimental}

\subsection{Materials and Reagents}

All the chemicals and reagents used in the present study were commercially available. These were purified by usual methods of distillation (for liquids) and crystallization from appropriate solvents (for solids). The organic solvents and other agents used in the work were cleaned and dried according to $[11,12]$. Analysis of complex compounds for metal content was performed according to [13, 14] and atomic absorption method on the Perkin-Elmer $3030 \mathrm{~V}$ spectrophotometer (USA), nitrogen was determined by the Dumas method, carbon and hydrogen-by burning in the oxygen current and on the Karlo-Erba-1106 element analyzer, the analysis data was calculated on the HEC-960 computer.

\subsection{Methods of Analysis}

ESR spectra of polycrystalline samples, liquid and frozen solutions in toluene and other solvents were taken on a Radiopan SE/X-2542 radio spectrometer with an operating frequency of $9.4 \mathrm{GHz}$. The magnetic field was calibrated using an NMR magnetometer. A stable radical, DPHG, was used as the standard. Experimental spectra were transmitted via a special interface to the SM-4 computer, which was used for theoretical reconstruction of ESR spectra. The parameters of the spectra were found by the method of the best approximation between experimental and theoretical spectra by minimizing the error functional according to the method described in $[15,17]$.

The ESR spectra of all compounds were studied in solutions pre-degassed in vacuum, toluene, chloroform, DMSO and pyridine. This is done in order to remove oxygen from solutions that widens the ESR lines. Toluene and chloroform were chosen as an inert solvent. The concentration of solutions was $10 \cdot 10^{-2}-10^{-6} \mathrm{M}$. In some cases, measurements of ESR spectra were performed on samples with an isotope of ${ }^{63} \mathrm{Cu}$ up to $99.8 \%$.

The static magnetic susceptibility of polycrystalline samples in the range $77-300 \mathrm{~K}$ was measured using the Faraday and Gui method at the facilities described in [16]. the obtained values were corrected for temperatureindependent Para magnetism and diamagnetism of ligands calculated according to the Pascal scheme $[15,16]$. the reference sample was $\mathrm{Co}\left[\mathrm{Hg}(\mathrm{CNS})_{4}\right]$.

Values of the MFF. monomer complexes were calculated using the formula:

$$
\mathrm{M}_{\text {eff. }}=2,83 \cdot\left(\chi_{\mathrm{aT}} \cdot \mathrm{T}\right)^{1 / 2}
$$

where, $\chi_{\mathrm{at}}=\chi_{\mathrm{M}}-\chi_{\text {dia. }}$.

Values of the MFF. dimer complexes of copper(II) were calculated using the formula:

$$
\mu_{\text {eff. }}=2,83 \cdot\left(\chi_{\mathrm{Cu}} \cdot \mathrm{T}\right)^{1 / 2}
$$

where $\chi_{\mathrm{Cu}}=0,5 \chi_{\mathrm{M}} ; \chi_{\mathrm{M}}=\chi_{\text {уд }} \cdot \mathrm{M}-\chi_{\mathrm{dia}}-2 \alpha \mathrm{N}$ (M is the molecular weight of the monomer, $\alpha$ is the impurity of the monomer). Error in the definition of the MFF. was $\pm 0,01 \mathrm{~m} . \mathrm{b}$.

\subsection{General Procedure for Preparation of Copper(II) Complexes with Methyl Hydrazones 5,5-dimethyl-2,4-dioxohexanoic Acid Ester}

Aroylhydrazines were synthesized based on the methyl esters of the corresponding acids and hydrazine hydrate using well-known methods [18]. to obtain thiobenzoylhydrazine, a carboxymethyl ether of dithiobenzoic acid was previously synthesized. Carboxymethyl ether of dithiobenzoic acid from benzyl chloride. Then $8.5 \mathrm{~g}$ of dithiobenzoic acid carboxymethyl ether was dissolved in $40 \mathrm{ml}$ of $1 \mathrm{n} \mathrm{NaOH}$ and $8 \mathrm{ml}$ of $50 \%$ hydrazine hydrate was added, while the solution discolored. After adding 10-15 ml of glacial acetic acid and cooling with ice, hydrazide crystals fell out. The precipitate was filtered out and recrystallized from benzene. The final product was obtained with $\mathrm{m}$. p. $70.5-71.55^{\circ} \mathrm{C}$, yield $(58 \%)$ which is characterized by [19-24, 31].

$\mathrm{CuL}^{1} \cdot \mathrm{NH}_{3}$. A hot solution of $1.25 \mathrm{~g}(0.005 \mathrm{~mol})$ of copper(II) acetate in $15 \mathrm{ml}$ of concentrated ammonia was added drop by drop to a solution of $1.52 \mathrm{~g}(0.005 \mathrm{~mol})$ of benzoyl hydrazone of methyl ether 5.5-dimethyl-2,4dioxohexanoic acid $\left(\mathrm{H}_{2} \mathrm{~L}^{1}\right)$ in $20 \mathrm{ml}$ of ethanol. A green solution is obtained, from which green crystals fall out after 5 minutes. The complex compound was filtered, repeatedly washed with water, and then with alcohol and dried in a vacuum desiccator over $\mathrm{P}_{2} \mathrm{O}_{5}$. Yields of $-0.95 \mathrm{~g}$.

Similarly, other copper(II) ammonia complexes were 
synthesized with the ligands $\mathrm{H}_{2} \mathrm{~L}^{1}-\mathrm{H}_{2} \mathrm{~L}^{4}$ and $\mathrm{H}_{2} \mathrm{~L}^{5}-\mathrm{H}_{2} \mathrm{~L}^{9}$, respectively (table 1).

Table 1. Yields and results of elemental analysis of complex copper(II) compounds based on acyl-and aroyl-hydrazones of methyl and ethyl ether of 2,4dioxocarboxylic acids.

\begin{tabular}{|c|c|c|c|c|c|c|c|c|c|c|}
\hline \multirow{2}{*}{ Complex } & \multirow{2}{*}{ Yield,\% } & \multicolumn{4}{|c|}{ Found, $\%$} & \multirow{2}{*}{ Brutto-formule } & \multicolumn{4}{|c|}{ Calculated, $\%$} \\
\hline & & $\mathrm{Cu}$ & C & H & $\mathbf{N}$ & & $\mathbf{C u}$ & C & H & $\mathbf{N}$ \\
\hline $\mathrm{CuL}^{1} \cdot \mathrm{NH}_{3}$ & 75 & 17,88 & 47,34 & 4,78 & 11,91 & $\mathrm{CuC}_{14} \mathrm{H}_{17} \mathrm{~N}_{3} \mathrm{O}_{4}$ & 17,91 & 47,39 & 4,83 & 11,84 \\
\hline $\mathrm{CuL}^{2} \mathrm{NH}_{3}$ & 66 & 15,82 & 41,96 & 4,01 & 14,08 & $\mathrm{CuC}_{14} \mathrm{H}_{16} \mathrm{~N}_{4} \mathrm{O}_{6}$ & 15,89 & 42,05 & 4,03 & 14,01 \\
\hline $\mathrm{CuL}^{3} \cdot \mathrm{Py}$ & 81 & 13,33 & 55,59 & 5,27 & 8,89 & $\mathrm{CuC}_{22} \mathrm{H}_{25} \mathrm{~N}_{3} \mathrm{O}_{5}$ & 13,38 & 55,63 & 5,30 & 8,85 \\
\hline $\mathrm{CuL}^{4} \cdot \mathrm{NH}_{3}$ & 53 & 15,97 & 51,38 & 5,79 & 10,64 & $\mathrm{CuC}_{17} \mathrm{H}_{23} \mathrm{~N}_{3} \mathrm{O}_{4}$ & 16,01 & 51,44 & 5,84 & 10,59 \\
\hline $\mathrm{CuL}^{4} \cdot \mathrm{Py}$ & 78 & 13,79 & 57,51 & 5,44 & 9,21 & $\mathrm{CuC}_{22} \mathrm{H}_{25} \mathrm{~N}_{3} \mathrm{O}_{4}$ & 13,84 & 57,57 & 5,49 & 9,15 \\
\hline $\mathrm{CuL}^{5} \cdot \mathrm{Py}$ & 70 & 12,06 & 48,08 & 4,18 & 8,13 & $\mathrm{CuC}_{21} \mathrm{H}_{22} \mathrm{~N}_{3} \mathrm{O}_{4} \mathrm{Br}$ & 12,13 & 48,15 & 4,23 & 8,02 \\
\hline $\mathrm{CuL}^{6} \cdot \mathrm{NH}_{3}$ & 57 & 14,39 & 51,81 & 6,37 & 12,77 & $\mathrm{CuC}_{19} \mathrm{H}_{28} \mathrm{~N}_{4} \mathrm{O}_{4}$ & 14,44 & 51,86 & 6,41 & 12,73 \\
\hline $\mathrm{CuL}^{7} \cdot \mathrm{NH}_{3}$ & 61 & 14,82 & 50,59 & 5,86 & 9,90 & $\mathrm{CuC}_{18} \mathrm{H}_{25} \mathrm{~N}_{3} \mathrm{O}_{5}$ & 14,88 & 50,64 & 5,90 & 9,84 \\
\hline $\mathrm{CuL}^{8} \cdot \mathrm{NH}_{3}$ & 70 & 15,97 & 51,38 & 5,79 & 10,54 & $\mathrm{CuC}_{17} \mathrm{H}_{23} \mathrm{~N}_{3} \mathrm{O}_{4}$ & 16,01 & 51,44 & 5,84 & 10,59 \\
\hline $\mathrm{CuL}^{9} \cdot \mathrm{Py}$ & 73 & 13,79 & 57,53 & 5,42 & 9,23 & $\mathrm{CuC}_{22} \mathrm{H}_{25} \mathrm{~N}_{3} \mathrm{O}_{4}$ & 13,84 & 57,57 & 5,49 & 9,15 \\
\hline
\end{tabular}

The interaction of alcohol solutions of the $\mathrm{H}_{2} \mathrm{~L}^{1}-\mathrm{H}_{2} \mathrm{~L}^{11}$ ligands with an aqueous ammonia solution of copper(II) acetate synthesized green fine-crystalline copper(II) complexes.<smiles>[R]C1=NN2C(C(=O)OC)=CC(C(C)(C)C)O[C@]2(N)O1</smiles>

Figure 1. Compound of the acyl-and aroylhydrazones ligans.

$\mathrm{R}=\mathrm{C}_{6} \mathrm{H}_{4} \mathrm{X}-n, \mathrm{X}=\mathrm{N}\left(\mathrm{CH}_{3}\right)_{2}\left(\mathrm{CuL}^{1} \cdot \mathrm{NH}_{3}\right), \mathrm{OCH}_{3}\left(\mathrm{CuL}^{2} \cdot \mathrm{NH}_{3}\right)$, $\mathrm{CH}_{3}\left(\mathrm{CuL}^{3} \cdot \mathrm{NH}_{3}\right), \quad \mathrm{H}\left(\mathrm{CuL}^{4} \cdot \mathrm{NH}_{3}\right), \quad \mathrm{Br}\left(\mathrm{CuL}^{5} \cdot \mathrm{NH}_{3}\right), \mathrm{NO}_{2}$ $\left(\mathrm{CuL}^{6} \cdot \mathrm{NH}_{3}\right), \quad \mathrm{R}=\mathrm{H} \quad\left(\mathrm{CuL}^{7} \cdot \mathrm{NH}_{3}\right), \quad \mathrm{CH}_{3} \quad\left(\mathrm{CuL}^{8} \cdot \mathrm{NH}_{3}\right), \mathrm{C}_{2} \mathrm{H}_{5}$ $\left(\mathrm{CuL}^{9} \cdot \mathrm{NH}_{3}\right)$, izo- $\mathrm{C}_{3} \mathrm{H}_{7}\left(\mathrm{CuL}^{10} \cdot \mathrm{NH}_{3}\right)$, tret. $-\mathrm{C}_{4} \mathrm{H}_{9}\left(\mathrm{CuL}^{11} \cdot \mathrm{NH}_{3}\right)$.

\section{Result and Discussion}

The obtained copper(II) copper oxides obtained from ESR spectra in a chloroform solution and toluene have a flatsquare structure. The ESR spectra are similar to the spectra of the previously studied compounds and represent a superposition of spectra from ${ }^{63} \mathrm{Cu}$ and ${ }^{65} \mathrm{Cu}$ nuclei $\left(\mathrm{I}_{\mathrm{Cu}} 3 / 2\right)$ with four HFS (Hyperfine Structure) lines. To reduce the width of the lines and improve the resolution of the spectra, the solutions of the complexes were degassed $[6,16,17,25]$.

It is established that the complexes obtained have an effective magnetic moment is equal to 1.73-1.74 $\mathrm{MB}$, calculated by the formula $\mu_{\text {eff }}=\sqrt{8 \chi^{1} \cdot m^{T}}$ practically independent of temperature. In the solid polycrystalline samples of these complexes there are no lines of "forbidden" transitions in low fields at $\mathrm{H} \cong 1700$ e (Figure 1) [25].

These indices of magnetic moments indicate that all the molecules of the complexes are monomeric and there is no antiferromagnetic exchange interaction between them [26].

The complexes studied in solutions have isotropic ESR spectra, analogous to those previously studied $[6,25]$ and are characteristic for mononuclear copper(II) complexes. These spectra have four HFS lines with different widths and intensities (Figure 2), representing the superposition of spectra from ${ }^{63} \mathrm{Cu}$ and ${ }^{65} \mathrm{Cu}$ nuclei $\left(\mathrm{I}_{\mathrm{Cu}}=3 / 2\right)$. All this unequivocally testifies to the flat-square structure of the coordinating node of Copper(II) with trans-located atoms $\left[\mathrm{N}_{2} \mathrm{O}_{2}\right]$. The different widths of the STS lines for nuclear spin projections are explained by the McConnell relaxation mechanism, the parameters of which are given in Table 2.

$$
\begin{gathered}
\mathrm{H}=\mathrm{g} \cdot \beta \cdot \mathrm{H}_{\mathrm{o}} \cdot \mathrm{S}+<\mathrm{a}_{\mathrm{Cu}}>\mathrm{I}_{\mathrm{cu}} \cdot \mathrm{S}+\mathrm{a}_{\mathrm{Nj}} \cdot \mathrm{I}_{\mathrm{Nj}} \cdot \mathrm{S} \\
\mathrm{H}=\alpha+\beta \cdot \mathrm{m}_{\mathrm{i}}+\gamma \cdot \mathrm{m}_{\mathrm{i}}^{2}
\end{gathered}
$$

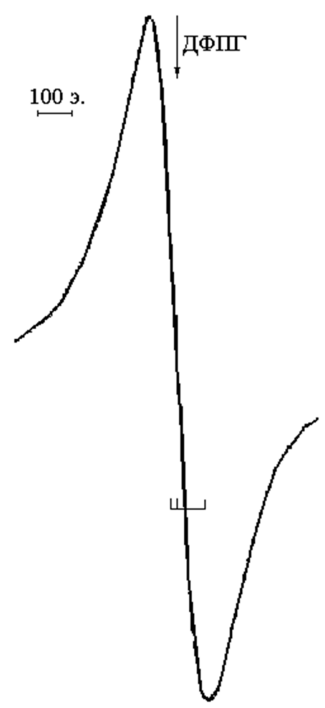

Figure 2. ESR spectrum of complex compound $\mathrm{CuL}^{4} \bullet \mathrm{NH}_{3}$ in solid form.

The spectra of all copper(II) complex compounds are described by an isotropic spin Hamiltonian (SH) of the form (1), where $\mathrm{g}$ is the measure of the effective magnetic moment of the electron, the dimensionless g-factor, that is, the ratio of the magnetic moment of the electron to its total angular momentum Landau (for a free electron $g=2.002322$ ), is the Bohr magneton, $S=1 / 2, I=3 / 2$ is the spin of the nucleus of $\beta$ the copper atom, In is the spin of the nucleus of the nitrogen atom. 
The width of the ESR spectra for complex copper(II) compounds is described by equation (4) [27], where it is taken into account that $\mathrm{mi}$ is the projection of the nuclear spin of the copper atom in the direction of the external magnetic field, $\alpha, \beta, \gamma$-are the coefficients due to various contributions to the relaxation mechanisms. In the copper(II) compounds studied, the unpaired electron is located on a molecular orbitals of the B1g type. According to this equation, $\alpha^{2}$ and $\left(\alpha^{\prime}\right)^{2}$-are the coefficients for the atomic orbitals of copper $\left(\mathrm{d}_{x^{2}-y^{2}}\right)$ and the atoms of the ligands $\left(\sigma_{\mathrm{i}}\right)$, respectively. The semantic value of the coefficient $\alpha$ in equation (5) can be expressed in terms of its square as the probability density of finding an unpaired electron on the orbital $\mid \mathrm{d} x_{x^{2}-y^{2}}>$. Then the quantity $\left(\alpha^{\prime}\right)^{2}$, of course, determines the degree of delocalization of the unpaired electron on the orbitals of the ligand atoms. If $\alpha^{2}$ and $\left(\alpha^{\prime}\right)^{2}$ are equal to 0.5 , then the metal-ligand bond in the complexes is covalent. In the case, if $\alpha^{2}=1$ and $\left(\alpha^{\prime}\right)^{2}=0$, the nature of the bond will be purely ionic. These coefficients $\alpha$ and $\alpha^{\prime}$ are related to each other by the normalization equation (6), where $\mathrm{S}$ is the overlap integral. The energy of the isotropic hyperfine interaction of the unpaired electron with the ligand nuclei is expressed by the equation (6) $[28,29]$, in this equation $\gamma_{\mathrm{N}}$-is the gyromagnetic ratio of the nitrogen atom, $\beta_{\mathrm{o}}$-is the Bohr magneton, $\beta_{\mathrm{N}}-$ is the nuclear magneton, $\rho_{\mathrm{N}}(0)$ is the density $2 \mathrm{~s}$-orbitals on the nucleus of the nitrogen atom. It should be noted that when $\left(\alpha^{\prime}\right)^{2}=0$, the unpaired electron is not on the ligand atoms and the DHFS disappears.

$$
\begin{gathered}
\alpha^{2}+\left(\alpha^{\prime}\right)^{2-} 2 \alpha \cdot \alpha^{\prime} \cdot \mathrm{S}=1 \\
<a_{N}>=\frac{4}{9} \pi \cdot \gamma_{N} \cdot \beta_{0} \cdot \beta_{N}\left(\alpha^{1}\right)^{2}\left|\rho_{N}(0)^{2}\right| S_{Z} \cdot I_{Z}
\end{gathered}
$$

If for the complex compound $\mathrm{CuL}^{1} \cdot \mathrm{NH}_{3}$, which has a cyclopentanone ring $\beta$-diketone fragment, the ESR parameters have the $\beta$ a substituent for the $\alpha^{2}=0.82$; value: $\mathrm{g}=2.099, \mathrm{a}_{\mathrm{Cu}}=89.53 \mathrm{e}, \mathrm{a}_{\mathrm{N}}=12.81 \mathrm{e}$, then for $\mathrm{CuL}^{4} \cdot \mathrm{NH}_{3}$ with a cyclohexane ring substituent these values are in the range: $\mathrm{g}=2,101, \mathrm{a}_{\mathrm{Cu}}=87,48 \mathrm{e}, \mathrm{a}_{\mathrm{N}}=13,02 \mathrm{e}, \alpha^{2}=0,82$ (Figure 2, Table 2). Such a slight change in the parameters of the ESR spectra indicates that an increase in the number of carbon atoms in cycloalkanones does not significantly affect the parameters of the ESR spectra as compared with $\beta$-diketone fragment of the ligand $\beta$ the perfluoroalcyl substituent of the molecule. Confirmation of the conclusions on the flat-square structure of copper(II) complexes in solutions of chloroform and toluene at room temperature, the value of the covalence degree of the copper-ligand bond calculated from the isotropic ESR parameters by formula (7):

$$
\alpha^{2}=\frac{1}{0,43}\left(\frac{a_{C u}}{0,036}+g-2\right)+0,02
$$

In the most intense fourth component of the HFS of the ESR spectrum of the complexes, the DHFS from nine lines from the nuclei of two non-equilibrated nitrogen atoms of the chelating ligand and the ammonia molecule should be resolved. According to theory, the cleavage constant from the nitrogen atom of the chelating ligand should be twice the splitting constant from the nitrogen atom of ammonia. The poor resolution of the DHFS from two non-equivalent nitrogen atoms (Figures 1, 2, Table 2) is apparently explained by the strong broadening of the DHFS lines under the influence of the electronegative ester radical adjacent to the metallocycle of the copper(II) ion [30, 31].

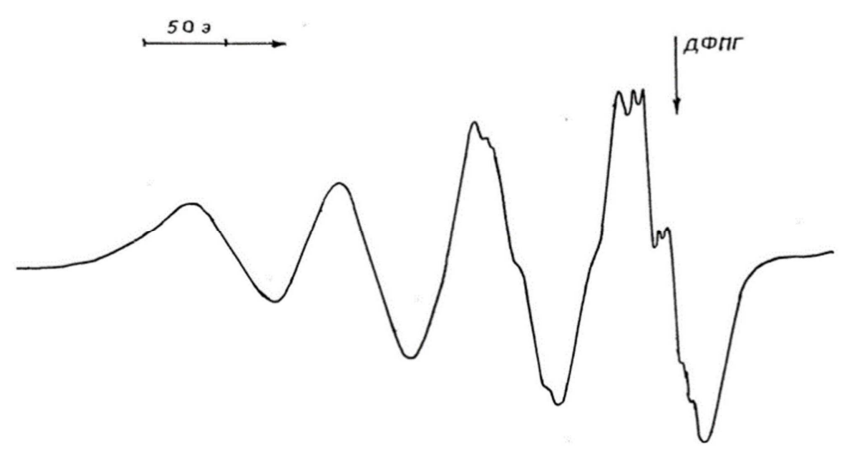

Figure 3. ESR spectrum of the complex compound $\mathrm{CuL} L^{I} \cdot \mathrm{NH}_{3}$ in a solution of chloroform at room temperature.

\begin{tabular}{|c|c|c|c|c|}
\hline Compounds & $\begin{array}{l}\mathrm{g}, \pm \\
\mathbf{0 , 0 0 1}\end{array}$ & $a_{\mathrm{Cu}}, \pm 0,01 \theta$ & $a_{\mathrm{N} 1 / \mathrm{N} 2}, \pm 0,01 \theta$ & $\alpha^{2}$ \\
\hline $\mathrm{CuL}^{1} \cdot \mathrm{NH}_{3}$ & 2.0967 & 91,09 & $15,8 / 7,9$ & 0,82 \\
\hline $\mathrm{CuL}^{2} \cdot \mathrm{NH}_{3}$ & 2,099 & 86,08 & 12,17 & 0,90 \\
\hline $\mathrm{CuL}^{3} \cdot \mathrm{NH}_{3}$ & 2,095 & 89,84 & 12,8 & 0,82 \\
\hline $\mathrm{CuL}^{4} \cdot \mathrm{NH}_{3}$ & 2,0961 & 93,19 & 13,5 & 0,82 \\
\hline $\mathrm{CuL}^{5} \cdot$ Pipe & 2,095 & 92,35 & $15,9 / 7,8$ & 0,84 \\
\hline $\mathrm{CuL}^{6} \cdot \mathrm{Py}$ & 2,093 & 90,56 & $16,02 / 8,0$ & 0,81 \\
\hline $\mathrm{CuL}^{7} \cdot \mathrm{NH}_{3}$ & 2,118 & 93 & $16,05 / 8,03$ & 0,84 \\
\hline $\mathrm{CuL}^{8} \cdot \mathrm{NH}_{3}$ & 2,0964 & 89,32 & $15,7 / 7,9$ & 0,83 \\
\hline $\mathrm{CuL}^{9} \cdot \mathrm{NH}_{3}$ & 2,0956 & 91,47 & $16,0 / 8,0$ & 0,83 \\
\hline $\mathrm{CuL}^{10} \cdot \mathrm{NH}_{3}$ & 2,097 & 89,94 & $15,8 / 7,8$ & 0,84 \\
\hline $\mathrm{CuL}^{11} \cdot \mathrm{NH}_{3}$ & 2,09 & 89 & $15,7 / 7,8$ & 0,84 \\
\hline
\end{tabular}

Table 2. Parameters of the ESR spectra of copper(II) complexes in a solution of toluene at room temperature.

\section{Conclusion}

Thus, by the method of ESR spectroscopy, by studying the magneto chemical properties of copper(II) complexes, it was established that these compounds in the solid state and in a solution of nonpolar solvents have a planar-square structure with a trans $-\mathrm{N}_{2} \mathrm{O}_{2}$ coordination sphere that passes to the octahedral through square-pyramidal when choosing highly polar solvents.

The complexes synthesized by us made it possible to create drugs that accelerate the convergence of seeds, the growth of cotton plants and protect it from wilt disease.

The analysis of these parameters shows that the introduction of electronic or electron-acceptor groups into the para-position of the benzene of the hydrazide fragment has negligible influence on the nature of the ESR spectra of copper complexes.

\section{Acknowledgements}

The authors are grateful to Academician, Professor of the 
National University of Uzbekistan Parpiev Nusrat Agzamovich and Professor Vadim Viktorovich Minin, Head of the Laboratory of Magnetic Materials Nikolai Nikolaevich Efimov and other employees of the Institute of General and Inorganic Chemistry of the Academy of Sciences of the Russian Federation for their practical assistance in preparing the article.

\section{References}

[1] Agrawal A., Sharma K. M., Prasad R. N. Synthesis and spectral studies of mixed ligand complexes of $\mathrm{Co}(\mathrm{II})$ with 5-nitrosalicylaldehyde and $\beta$-diketones, hydroxyaryl aldehydes or ketones // Pol. J. Chem.-2007.-81.-N 12.-P. 2081-2087.

[2] Pakalnis V. A., Ozerova I. V., Yakimovich S. I., Yershov A. Yu., Lagoda I. V. Heterocycles based on aroylacetic aldehydes and SH-containing hydrazides / / Journal of organic chemistry. - 2009. - Vol. 45. - No. 2. - Pp. 295-300.

[3] Geraldes C. F. G. C., Barros M. T., Maycock C. D., Silva M. I. The Preferential Direction of Enolization of Some Asymmetric 1,3-Dicarbonyl Compounds in Solution: a Study by Multinuclear NMR Spectroscopy // J. Mol. Struct.-1990.V. 238.-P. 335-346.

[4] Sevinchova D. N., Umarov B. B. Nickel(II) and zinc(II) Complexes with acylhydrazones of b-ketoaldehydes / Proceedings of the regional scientific-practical conference of young scientists and students under the slogan "XXI century the century of intellectual generation." - Bukhara State University. - Bukhara. - June 18-19, 2013.-Pp. 223-225.

[5] Sevinchov N. G., Umarov B. B., Avezov K. G., Abdurakhmonov S. F. Derivatives and complexes of ketoaldehyde and keto ethers / Materials of the I REP. Conf. with international participation "Green chemistry for sustainable development".- SamSU, Samarkand, March 26-28, 2012.-Pp. 242-243.

[6] Umarov, B. B. Complex compounds of some transition metals with bis-5-hydroxypyrazolines. Dis.... Doct. chem. Science. Tashkent: IU AN RUz., 1996. - 351 p.

[7] Zhang J.-P., Zhang J.-P., Zhang Y.-B., Lin J.-B., Chen X.-M. Metal Azolate Frameworks: From Crystal Engineering to Functional Materials // Chem. Rev.-2012. - V. 112.- P. 1001-1033.

[8] Zou R., Abdel-Fattah A. I., Zhao H. Xu Y., Hickmott D. D. Storage and separation applications of nanoporous metalorganic frameworks // Cryst Eng Comm.- 2010.- V. 12.- P. 1337-1353.

[9] Gusev A. N., Shulgin V. F., Ugolkova E. A., Efimov N. N., Alexandrov G. G., Minin V. V., Eremenko I. L. bionuclear complexes of copper(II) based on functionalized 1,2,4triazoles: Synthesis, structure and magnetic properties. chemistries. - 2014. - Vol. 59. - C 910-916.

[10] Kawamoto T., Kushi Y. Three Types of Nickel(II) Complexes Derived from 2-Substituted Benzothiazoline; Formation of a Tetranuclear Complex by a Sterically Induced Orthometallation Reaction // Bull. Chem. Soc. Jpn.- 2004.Vol. 77.- N. 2.- P. 289-294.

[11] Weigand-Hilgetag. Experimental methods in organic chemistry. Translation from it. language edited by Prof. N. N. Suvorov.- M.: Chemistry. 1968. - Pp. 847-886.

[12] Reutov O. A., Kurts A. A., Butin K. P. Organic chemistry. Textbook for higher Education institutions. - Moscow: MSU Publishing house, 1999. - part I.-560 p.

[13] Douglas A. Skoog, Donald M. West, F. James Holler, Stanler R. Crouch. Fundamentals of Analytical Chemistry. Brooks/Cole, C, Cengage Learning, 2014.- 958 p.

[14] Robinson J. W., Frame E. M., Frame G. M. II. Undergraduate Instrumental Analysis Sixth edition / Marcel Dekker New York, 2005. - 1107 p.

[15] Rakitin Yu. V., Larin G. M., Minin V. V. Interpretation of ESR spectra of coordination compounds.- Moscow.- Science.1993.-P. 400.

[16] Karlin R. Magnetochemistry. M.: Mir. 1989. 400 p. (in Russian).

[17] Larin G. M., Shulgin V. F., Sarnit E. A., Rakitin Yu. V. ESR Study of weak exchange interactions in copper(II) binuclear complexes with salicylic aldehyde acylhydrazones // News of the Academy of Sciences. Chemical series.- 2001. - № 5. - P. 777-783.

[18] Modern problems of synthesis and research of organic compounds. Edited By R. R. Kostikov, L.: publishing house of the Leningrad state University.- 1990. - 156 p.

[19] Ribbons, DouglasáW. "Synthesis of 2, 4-diketoacids and their aqueous solution structures." New journal of chemistry 23.4 (1999): 437-446.

[20] Verbić, Tatjana, et al. "An LFER study of the protolytic equililbria of 4-aryl-2, 4-dioxolbutanoic acids in aqueous solutions." Journal of the Serbian Chemical Society 72.12 (2007): 1201-1216. Verbic, Tatjana Z., et al. "The Effect of Phenyl Substituents on." Letters in Organic Chemistry 5.8 (2008): 692-699.

[21] Kizimovaa, I. A., et al. "Chemistry of Iminofuran: XVI. Synthesis, Structure, Biological Activity, and Cyclization of 4-Oxo-2-(2-phenylaminobenzoyl-hydrazono) butanoic Acids." Russian Journal of Organic Chemistry 55.11 (2019): 17041711.

[22] Emerson, David W., Richard L. Titus, and Rowena M. Gonzalez. "Evidence for ketene intermediates in the decarbonylation of 2, 4-dioxo acids and esters and 2oxobutanedioic acid esters." The Journal of Organic Chemistry 56.18 (1991): 5301-5307.

[23] Tursunov, M. A., B. B. Umarov, and K. G. Avezov. "Synthesis and Crystal Structure of Nikel (II) and Zinc (II) Complexes with Benzoylacetic Aldehyde Derivatives." Moscow university chemistry bulletin 74.3 (2019): 138142.

[24] Tursunov, M. A., et al. "Synthesis and Crystal Structure of the Nickel (II) Complex with Aroyl Hydrazone of Ethyl Ether of 5, 5-Dimethyl-2, 4-Dioxohexane Acid." Journal of Structural Chemistry 61.1 (2020): 73-85.

[25] Yusupov V. G. Complex compounds of transition metals on the basis of acyl-, thioacylhydrazones and their cyclic tautomers. Dis.... Doct. chem. Sciences. Tashkent: IU AN RUz.-1990. - 407 p. 
[26] Abduraxmonov, Sayfiddin Fayzullayevich, et al. "Binuclear complexes of nickel(II) based on the condensation products of acetylpinacoline with oxalic and malonic acid dihydrazides." Scientific Bulletin of Namangan State University 1.6 (2019): 73-80.

[27] Abdurakhmonov, S. F., Xudoyarova E. A., Umarov B. B.. "Theoretical aspects of weak exchange interaction in the ESR spectra of homobinuclear complexes of copper(II)." International Journal of Advanced Research in Science, Engineering and Technology 6.9 (2019): 10665-10701.

[28] Avezov, K. G., et al. "Nickel (II) complexes based on products of condensation of aroyl (perfluoroacyl) methanes with benzoylhydrazine." Russian Journal of Coordination Chemistry 37.4 (2011): 275-280.
[29] Avezov, K. G., et al. "Copper(II) complexes based on 2thenoyltrifluoroacetone aroyl hydrazones: Synthesis, spectroscopy, and X-ray diffraction analysis." Russian Journal of Coordination Chemistry 42.7 (2016): 470-475.

[30] Parpiev N. A., Yusupov S. I., Yakimovich S. I., Sharipov Kh. T. Acylhydrazones and their complexes with transition metals. - Tashkent.- Fan.- 1988.- 161 p.

[31] Umarov B. B., Tursunov M. A., Minin V. V. Complexes with derivatives of ketoaldehydes and ketoesters, Monographs. Tashkent. -"Nishon-Noshir" -2016 - P. 350.

[32] Malinina, Elena A., et al. "Structure and magnetic properties of trinuclear copper(II) complex [Cu3 (bipy) 6 ( $\mu 3$ CO3)][B12H12] 2- 4.5 DMF- 2H2O." Inorganica Chimica Acta 479 (2018): 249-253. 